\title{
Observing System Simulation Experiments and Adjoint Sensitivity Analysis: Methods for Observational Programs in the Arctic Ocean
}

\author{
Oceana Francis, ${ }^{1}$ Gleb Panteleev, ${ }^{2}$ Max Yaremchuk, ${ }^{2}$ Vladimir Luchin, ${ }^{3}$ Jacob Stroh, ${ }^{4}$ Pamela Posey ${ }^{2}$ \\ and David Hebert ${ }^{2}$
}

(Received 30 November 2016; accepted in revised form 13 April 2017)

\begin{abstract}
Over recent decades, the Arctic Ocean (AO) has experienced profound climate changes. To study these climate changes, several regional observational programs have been started. Because of complicated logistics and remoteness, in situ observations in the $\mathrm{AO}$ are extremely expensive. Therefore, an efficient ocean observational system in the $\mathrm{AO}$ is critical to understand environmental changes in the Arctic. Observing System Simulation Experiments (OSSEs) and Adjoint Sensitivity Analysis (ASA) are powerful tools that could be used in the optimization of existing and incoming observational programs in the AO. These optimal planning tools recommended by the Study of Environmental Arctic Change (SEARCH) implementation plan, and widely used in atmospheric research, are still rarely implemented in physical and biological oceanography. We provide several examples of how the OSSE and ASA can be used to optimize the locations of high frequency radars and biological tracer surveys and leveraged toward creating an inexpensive drifter observational program capable of providing sufficient information to reconstruct the circulation in the northern Bering, Chukchi, and southern Beaufort Seas.
\end{abstract}

Key words: Arctic Ocean; optimization observational programs; adjoint sensitivity analysis; observing system simulation experiments

RÉSUMÉ. Ces dernières décennies, l'océan Arctique (OA) a connu des changements climatiques d'envergure. Plusieurs programmes d'observation régionaux ont été mis en œuvre pour étudier ces changements climatiques. En raison de la complexité de la logistique et de l'éloignement, les observations sur place dans l'OA coûtent extrêmement cher. Par conséquent, un système efficace d'observation des océans dans l'OA s'impose pour comprendre les changements environnementaux qui se produisent dans l'Arctique. Les observations expérimentales (Observing System Simulation Experiments, ou OSSE) et la méthode adjointe d'analyse de sensibilité (Adjoint Sensitivity Analysis, ou ASA) sont d'importants outils susceptibles d'être utilisés dans l'optimisation des programmes d'observation actuels et futurs dans l'OA. Ces outils de planification optimaux sont recommandés par le plan de mise en œuvre de l'étude sur le changement environnemental dans l'Arctique (Study of Environmental Arctic Change, ou SEARCH) et sont largement utilisés dans la recherche atmosphérique, bien qu'ils soient encore rarement employés en océanographie physique et biologique. Nous fournissons plusieurs exemples de la façon dont les OSSE et l'ASA peuvent permettre d'optimiser l'emplacement des radars à haute fréquence et des levés de traceurs biologiques. De plus, elles peuvent stimuler la création d'un programme d'observation de bouées dérivantes peu coûteux pouvant fournir suffisamment d'information pour la reconstruction de la circulation dans les mers de Béring et des Tchouktches au nord, et dans la mer de Beaufort au sud.

Mots clés : océan Arctique; programmes observationnels d'optimisation; méthode adjointe pour l'analyse de sensibilité; observations expérimentales (Observing System Simulation Experiments)

Traduit pour la revue Arctic par Nicole Giguère.

\section{INTRODUCTION}

With the diminishing of sea ice during the past decades, we have been observing significant changes in the hydrophysical conditions in the Arctic Ocean. An incomplete list of observed changes includes: (1) the intensification of warm Pacific Water inflow through the
Bering Strait, which causes changes to the freshwater balance in the Strait and the Eurasian Basin (Woodgate et al., 2012); (2) an enhanced Arctic Ocean Oscillation index "due to a cyclonic (anti-clockwise) shift in the ocean pathway of Eurasian runoff forced by strengthening of the west-to-east Northern Hemisphere atmospheric circulation" (Morison et al., 2012:66); (3) amplification of the regional

\footnotetext{
${ }^{1}$ Department of Civil and Environmental Engineering and Hawai’i Sea Grant, University of Hawai’i at Manoa, Honolulu, Hawaii 96822, USA; ofrancis.hawaii.edu

${ }^{2}$ Naval Research Laboratory, Stennis Space Center, Mississippi 39529, USA

${ }^{3}$ V.I. Il'ichev Pacific Oceanological Institute, Far Eastern Branch of Russian Academy of Sciences, Vladivostok 690041, Russia

${ }^{4}$ International Arctic Research Center, University of Alaska Fairbanks, PO Box 757335, Fairbanks, Alaska 99775, USA

(C) The Arctic Institute of North America
} 
significant wave height by $35 \%$ (Francis et al., 2011); (4) development of a new role for sea waves to further diminish Arctic sea ice (Simmonds and Rudeva, 2012); and (5) enhanced vertical mixing (Qiao et al., 2004). There is also a significant increase of human activity in the Arctic Ocean, which includes trans-Arctic transportation and shipping, mineral extraction, and oil and gas exploration in the Arctic shelf. The increased shipping activity inevitably increases the probability of accidents and technological disasters, such as sinking ships, oil spills, and contamination of the ocean from transiting ships onto coastal infrastructure. Therefore, there is a strong need to organize an efficient observational network $(\mathrm{ON})$ in order to control undesirable events and minimize their impact on the local fragile ecosystem, in case of an event.

An efficient $\mathrm{ON}$ would allow for a reliable estimation of the observed changes; explain the most important factors responsible for the observed changes; forecast future changes to the Arctic Ocean's hydrophysical, hydrochemical, and ecological states; and aid in the response to undesirable events. The latter is usually suggestive of an option that involves the operational hindcast or forecast of the circulation for a region with intense human activity.

The need for better understanding of physical and ecosystem processes has resulted in several observational initiatives such as the Nansen and Amundsen Basins Observational System (NABOS), the Beaufort Gyre Exploration Project (BGEP), the East Siberian Shelf Study (ESSS), and the Distributed Biological Observatory (DBO). Recently, the North Pacific Research Board (NPRB) initialized the Arctic Integrated Ecosystem Research Program (AIERP), which is a continuation of other similar studies in the northern Bering Sea. Oil exploration activity on the Alaskan Shelf resulted in the deployment of high frequency radar (HFR) systems along the northern Alaskan coast. There are several other smaller-scale observational activities in the Pacific Sector of the Arctic Ocean conducted by the international research community from Russia, Japan, China, and Korea, which are organized into the Pacific Arctic Group (PAG).

The essential elements of modern observations in the Arctic Ocean include velocity observations from moorings and coastal HFRs and hydrographical observations from ships. Currently, there are a significant number of moorings deployed in the Pacific side of the Arctic Ocean in the frame of a multinational effort. However, such observational plans are usually based on a qualitative understanding of the investigated processes, scientific intuition or both, which may be at least sub-optimal or subjective.

While conductivity/temperature/depth (CTD), biological, and hydrochemical observations are usually available immediately, observations from moorings are available only 1-2 years after deployment, which creates a significant delay in the analysis of these hydrophysical, biological, and hydrochemical observations. Also, velocity observations from moorings cannot provide the information needed for an operational hindcast or forecast of the regional circulation. In regions with intensive circulation (e.g., Bering Strait, Herald and Barrow Canyons), the advection of the biological and hydrochemical tracers should be taken into account when obtaining a more accurate interpretation and analysis of collected observations (Panteleev et al., 2004, 2015).

Therefore, an ideal ON plan should be guided by an objective strategy that optimizes the expense of monitoring coastal circulation in the context of existing activity and existing needs. The prerequisite for developing such a strategy is the ability to answer the following questions:

- How many observations do we need in order to obtain reliable estimates of various target quantities (TQs) (such as transports through certain sections, surface circulation) in these regions? Further, what is the relative impact of additional observations?

-What are the optimal locations for glider-based scanning, mooring deployment, and HFR installation? What is the optimal combination between these instruments?

- How do observations in one region (e.g., velocity observations at particular sites in the Chukchi Sea) correlate with observations in another region (e.g., with observations in the Bering Strait)?

- In what regions do we need improved coverage and what are the requirements for observational accuracy?

Indeed, these questions typically arise during the planning of any field experiment. For example, this planning may include how to derive more accurate estimates of the Atlantic Water transport along the continental slope (NABOS, 2016) or the accumulation of freshwater in the Beaufort Sea (BGEP, 2016) using a limited number of moorings under the condition that there are additional observations from ice-tethered profilers (WHOI, 2017) or J-CAD profiles (JAMSTEC, 2017). It is possible to provide an unlimited number of similar questions relating to the optimization of the observations.

Thus, given the high expense of observational instrumentation and deployment logistics in the Arctic region, the first step in an ON (or any other field experiment) development should be the preliminary analysis and optimization of current observations and future observational plans. For example, when located in appropriate sites along the Alaskan coastline, HFRs can be effectively used to support local marine transportation and offshore operations and thereby provide benefit to local communities and businesses. Simultaneously, these data can contribute to numerous scientific projects of climatological importance, such as the monitoring of the Bering Strait transport and the Alaska coastal currents.

Tools for the objective planning of observation systems are well known and include Observing System Simulation Experiments (OSSEs) and the Adjoint Sensitivity Analysis (ASA). They are widely applied for analysis and the planning of observational networks in 
operational meteorology, where the corresponding volume of observations is critical for accurate weather forecasting (Lahoz et al., 2005; Errico et al., 2013; Timmermans et al., 2015). Over the past decades, there have also been persistent efforts to introduce a similar approach for ocean observational programs (Bennet, 1985; Barth and Wunsch, 1990; Barth, 1992; Beckers and Rixen, 2003; Panteleev et al., 2004). Despite these attempts, optimal planning of oceanographic surveys, programs, and longterm monitoring are still rare and usually do not include quantitative estimates of the efficiency of the proposed observational plans.

In this paper, we describe the basic ideas behind the ASA and OSSE techniques, and show how the application of these tools may help to optimize the location of the HFRs, identify the gaps in the existing observational programs, justify a drifter observational program, and increase the information content of various passive-tracer observations collected during ship surveys.

\section{APPROACHES}

Currently, there exist two well-established techniques for optimizing ONs. Both of them make extensive use of the link between numerical models and observations and may be used in sequence.

First, one would perform OSSEs in order to identify optimal in situ observing site locations, the required measured frequency, and acceptable levels of uncertainty. The conventional idea underlying OSSEs is to simulate "data" using some referenced model solution as a "true nature state," contaminate these data with noise (mimicking observational and modeling errors), and then reconstruct the "true state" from these "data." The schematic of this procedure is shown in Fig. 1. The OSSE can be used to evaluate the hindcast and forecast model solutions as well. The ancestor of the OSSE approach is a well-known twindata assimilation experiment procedure, which is a basic method of testing data assimilation schemes developed during the last couple of decades.

The application of the OSSEs for planning expensive oceanographic experiments is rare, but does exist. For example, OSSEs were used for estimating errors in the observing network with the goal of quantifying dense water volume formation in the northwestern Mediterranean Sea during 2012-13 (Waldman et al., 2016).

Second, one could analyze the dynamically induced correlations between any TQ and observations through ASA (Köhl and Stammer, 2004; Panteleev et al., 2009). This approach requires the use of tangent linear and adjoint models (Marchuk, 1995; Wunsch, 1996), which may be problematic for some models and may require timeconsuming development if the models are not already available.

A four-dimensional variational (4D-Var) data assimilation procedure is used to transform an a priori data

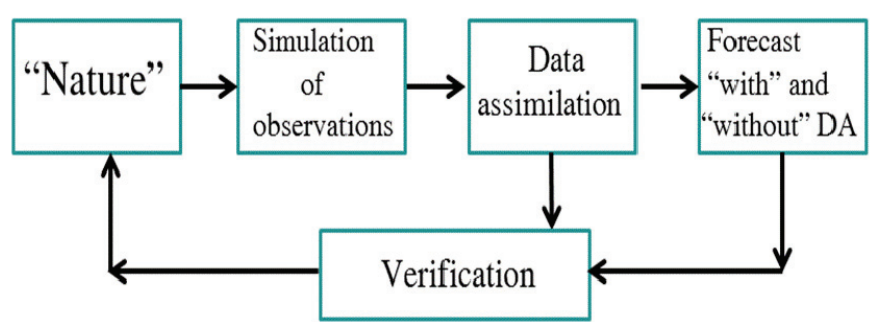

FIG. 1. Schematic of the typical observing system simulation experiment. $\mathrm{DA}=$ data assimilation

probability distribution by injecting dynamical information. The 4D-Var DA procedure establishes dynamically constrained correlations between any functions $\boldsymbol{L}(\boldsymbol{y})$ of the ocean state variables $\boldsymbol{y}$ whose evolution is described by $\boldsymbol{y}=\boldsymbol{M c}$, where $\boldsymbol{M}$ is a numerical model operator and $\boldsymbol{c}$ is the control vector containing poorly known model entries, such as initial and boundary conditions. The quality of the model solution $\boldsymbol{y}$ is usually evaluated against observations by means of a quadratic cost function $J(y)$, which has the sense of an argument of the multi-variate Gaussian probability density function $P \sim \exp (-J)$. The cost function is minimized with respect to $c$ to obtain the "most probable" state of the ocean. As a consequence, a posteriori probability density in the vicinity of the optimal state is also Gaussian, with inverse covariance $\mathbf{H}=\partial^{2} J / \partial \boldsymbol{c}^{2}$. Under the assumption that variations of the control variables around the optimal state are not too large, the covariance between two quantities $q_{1}$ and $q_{2}$, expressed in terms of the control vector $c$ as $q_{1}=$ $\mathbf{L}_{1} \boldsymbol{y}=\mathbf{L}_{1} \mathbf{M} \boldsymbol{c}$ and $q_{2}=\mathbf{L}_{2} \mathbf{M} \boldsymbol{c}$, is $\operatorname{cov}\left(q_{1}, q_{2}\right)=\mathbf{L}_{1} \mathbf{M} \mathbf{H}^{-1} \mathbf{M}^{\mathbf{T}} \mathbf{L}_{2}{ }^{\mathbf{T}}$. Here, superscript $\mathbf{T}$ denotes transposition and $\mathbf{M}, \mathbf{L}_{1,2}$ are respectively the model operator and operators relating $q_{1,2}$ to the model state $\boldsymbol{y}$, which are linearized in the vicinity of the optimal solution. Magnitude $S$ of $\operatorname{cov}\left(q_{1}, q_{2}\right)$ may be used to estimate the sensitivity of a target quantity (say, $q_{2}$ ) to an observation of $q_{1}$ in the presence of other data and dynamical constraints, defined by the structure of $\mathbf{H}^{-1}$. Following this framework (Baker and Daley, 2000; Cacuci, 2003; Kohl and Stammer, 2004), one can investigate sensitivity of the optimized "most probable" value of a target quantity $q_{2}$ to observations of $q_{1}$ by estimating the magnitude of the derivative $S=\delta q_{2} / \delta q_{2}$. The major difficulty with this technique is the enormous size of $\mathbf{H}^{-1}$, which makes the direct estimation of $S$ barely feasible for state-of-the art numerical models. For these reasons, sensitivity computations are often made under simplifying assumptions (see Appendix 1). In this paper, we present the results of a sensitivity analysis under the assumption that prior error variances $(\sigma$ of $\boldsymbol{c}$ ) are smaller than the combined observational and representation error variances, and we estimate the values of $\sigma$ from the statistics of the model/data misfits of the U.S. Navy's Arctic Cap Nowcast/Forecast System (ACNFS) data assimilative model. In addition, we employ a low-order approximation of $\mathbf{H}^{-1}$ in the resulting sensitivity relationship $S=\operatorname{Tr}\left[\mathbf{R}^{-1} \operatorname{cov}\left(q_{1}, q_{1}\right)\right]^{1 / 2}$, where $\mathbf{R}$ is the error variance in observing $q_{1}$ (see Appendix 1). 


\section{OPTIMAL POSITIONING OF HFR}

OSSEs and ASA can be used separately or in combination (Panteleev et al., 2015). The difference between these approaches is that the ASA is usually applied to states that were previously optimized from the available data, whereas the statistical analysis of OSSEs is usually applied to non-optimized model solutions, which may differ significantly from the true state of the ocean. As shown above, the ASA is based on the deterministic relationship between observations and model state, which is the basic advantage of the 4D-Var data assimilation approach based on tangent linear and adjoint modeling. The technique allows one to analyze the impact of any additional observations on the optimized model state, and then project this to any TQ of interest. These steps are formally described as applications of linear operations on the model state. The reverse algorithm is also possible and usually less expensive.

The key result of an ASA is an adjoint sensitivity map that establishes a formal relationship between the TQ and all elements of the model state. Fig. $2 b$ shows a time-averaged ASA map of the mean Bering Strait transport sensitivity to the surface velocity observations for the case of a slowly varying summer climatological circulation (shown in Fig. 2a) (Panteleev et al., 2015). Roughly speaking, Fig. $2 b$ indicates that total transport through the Bering Strait is most strongly correlated with (observed) velocity values in the areas of maximum sensitivity, so that the HFR pair denoted by ' 45 ' (Diomede Islands and Wales, Fig. 2c) best measures the TQs of mass, heat, and salt transport through the strait. An immediate conclusion is that if we have one mooring and want to measure the Bering Strait transport, it should be deployed in the American part of the Strait. Planning the deployment of multiple moorings would require a more complicated analysis taking into account an adaptive sampling strategy (Bishop et al., 2001; Daescu and Navon, 2004), or conducting multiple OSSEs as in Panteleev et al. (2013a).

HFRs observe surface velocity along the beams, which project radially outward from the antenna with a radius of about $200-250 \mathrm{~km}$ (see Fig. 2b). Therefore, it is necessary to account for a more complicated "observational operator" corresponding to the HFR configuration. This operator takes into account the area covered by the HFR observations as well as the spatial orientation of the rays along which the observations occur. Further, the operator should account for the decreasing accuracy of the HFR observations as distance increases from the antenna, since observations near the HFR site are usually more accurate than those farther away. Technical details for the construction of the HFR observation operator and error covariance approximation can be found in Panteleev et al. (2015).

By applying simple algorithms that take into account the geographical location of different HFRs on the adjoint sensitivity map (see Fig. 2b), we can easily estimate the
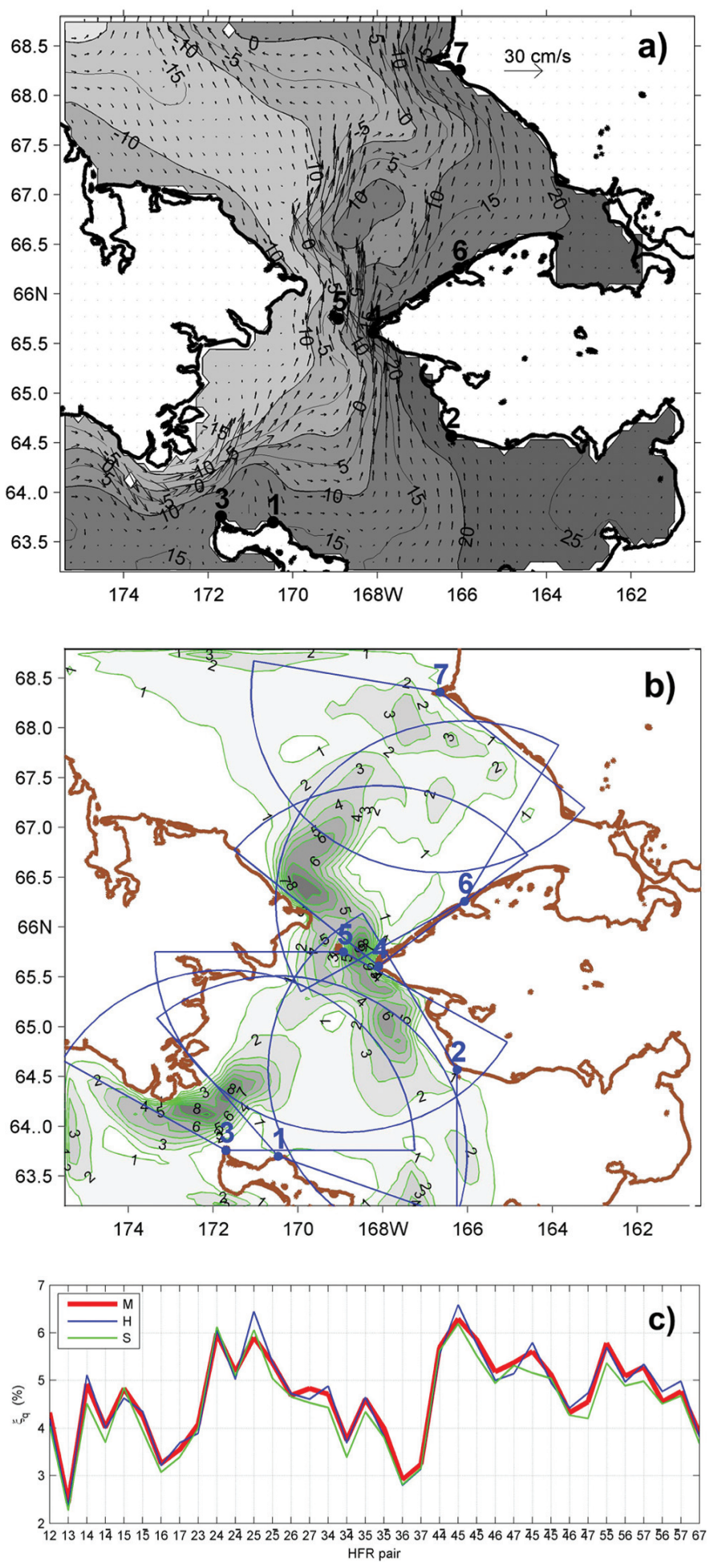

FIG. 2. a) Surface current and sea surface height in the Bering Strait region. b) Time-averaged map of the mean Bering Strait transport sensitivity to surface velocity observations. Sensitivity values are normalized by their maximum at the Bering Strait. Numbers 1-7 designate possible sites for high frequency radars (HFRs) near the villages along the Alaskan coast: (1) Savoonga, (2) Sinuk, (3) Gambell, (4) Wales, (5) Diomede, (6) Shishmaref, and (7) Point Hope. c) Relative reduction of the errors in the estimation of momentum $(\mathrm{M})$, heat $(\mathrm{H})$, and salt $(\mathrm{S})$ transports through the strait for various pairs of HFRs. Numbers labeling HFR pairs correspond to locations in Fig. 1b. Bars over Wales (point 4) and Diomede (point 5) locations denote northward-looking antennas at those sites. 
reduction of the Bering Strait transport errors using observations from any HFR pair and the efficiency of those pairs. As noted above, Fig. 2c shows that two HFRs located in Diomede and Wales (pair ' 45 '), looking south, will provide the least estimation error of the Bering Strait transport. The other reasonable combinations are HFR installations in Sinuk and Wales (pair '24'), Sinuk and Diomede (pair ' 25 '), and two HFRs in Wales looking to the north and south. Since an installation in Diomede is logistically complicated (Fang et al., 2017), the HFR configurations at Sinuk-Wales and Wales-Wales are reasonable sub-optimal alternatives to the Diomede-Wales setup. Note, however, that deployment at Wales-Wales may be significantly cheaper.

It is worth noting that the northward-looking Diomede and Wales radar pairs demonstrate a somewhat smaller error reduction compared to a southward-looking configuration. The increased efficiency of the southward-facing HFR is due to the longer residence time of the observed information as it propagates through the computational domain. Similar effects have also been obtained in the efficiency analysis of hydrophysical surveys (Panteleev and Semenov, 1988; Panteleev et al., 2004).

It is also evident that, compared to the volume transport, the curves for the heat and salt transport error reductions demonstrate higher peaks for the Sinuk-Diomede and Sinuk-Wales pairs $(6.3 \%$ and $6.1 \%$, respectively). This higher error reduction for the Sinuk-Diomede and SinukWales HFR configuration can be explained by the fact that heat and salt transports from July to September are particularly sensitive to variations in the temperature and salinity fields of the eastern part of the domain, where large riverine inflow of fresh and warm water from Alaska drive strong horizontal gradients.

The financial constraints may be technically incorporated into the algorithm, so in practice the WalesWales pair can be found as a "best" solution when logistical expenses of installation and maintenance are included in the optimization. Simultaneously, considering both financial and scientific (Bering Strait transport) values requires a relative weighting of these factors. This weighting introduces subjectivity into the process, and it is therefore reasonable to avoid the economic aspects when pursuing an objective analysis.

Interestingly, placement of the oppositely directed HFRs at Diomede and Wales ( $4 \overline{4}$ and $5 \overline{5}$ configurations in Fig. $2 \mathrm{c}$ ) also results in a fairly good reduction of error $(\varepsilon=5 \%-8 \%)$ despite the fact that HFR coverage areas do not intersect for these configurations. The result could be explained by the fact that such configurations cover a much larger area from both sides of the Bering Strait with strong sensitivities (Fig. 2b) and weakly correlated (independent) observations. Such a choice of observation points is capable of providing a fairly large amount of information on the magnitude and redistribution of the Bering Strait throughflow because the measured radial velocities tend to be aligned in the principal direction of the flow.
TABLE 1. The different high frequency radar (HFR) pair configurations and the absolute difference between the true and assimilated Bering Strait transport values. Optimization was done using simulated data from HFR pairs shown in the left column.

\begin{tabular}{lc}
\hline \hline High frequency radar pairs & Bering Strait error (Sv) \\
\hline Diomede-Wales & 0.084 \\
Sinuk-Wales & 0.129 \\
Diomede-Diomede & 0.177 \\
Savoonga-Sinuk & 0.285 \\
Savoonga-Gambell & 0.454 \\
Diomede-Point Hope & 0.239 \\
\hline \hline
\end{tabular}

The outlined algorithm can be easily extended to optimize installation locations and analyze ON efficiency for more than two HFRs, since formally an unlimited number of HFRs can be included into the observational operator $\boldsymbol{L}_{1}$. This analysis is computationally feasible since the number of possible locations to deploy HFRs is usually limited by the relatively high cost of HFRs $(\sim 500000)$ and the limited number of coastal locations that are logistically convenient for an HFR installation.

In addition, we can conduct multiple OSSEs and validate the results inferred from the adjoint sensitivity maps and other byproducts of the ASA technique. To conduct an OSSE, the HFR data was extracted from the referenced (climatological) solution.

The simulated HFR data for a tested pair of locations was assimilated into the Semi Implicit Ocean model using the 4D-Var algorithm (Panteleev et al., 2010). The first-guess solutions started from the geostrophically balanced state corresponding to the July climatology of temperature and salinity. After assimilating the HFR data, transport through the Bering Strait was computed and the root mean square differences between reconstructed and true transport were estimated.

A fairly good agreement exists between the OSSEs and the results of the 487 sensitivity analyses discussed above: the best HFR configurations are for the Diomede-Wales, Sinuk-Wales, and for the oppositely directed antennas on Diomede Island (Table 1). The Diomede-Point Hope and Savoonga-Sinuk pairs demonstrate significantly larger discrepancies, with the worst result from the SavoongaGambell pair. Note, however, that the ASA approach needs the analysis of one adjoint sensitivity map (see Fig. 2b), which can be easily accomplished for any possible HFR configuration, while a very high number of moorings and possible sites for deployment requires running many OSSEs, which can be computationally prohibitive.

\section{OPTIMAL PASSIVE TRACER SURVEY}

The ASA technique is a sensitivity analysis, which formally involves computation of the TQs' derivatives (such as the mass, heat, and salt transports above) with respect to observations. This computation requires the differentiability of the observation operator, so the ASA 
approach can only apply to certain kinds of observation systems. In the case of non-differentiable observational operators, OSSEs are probably the only way to optimize ONs. An important example giving rise to nondifferentiable observational operators are passive tracer surveys, a method of observation that is typically used in the study of the Arctic Ocean ecosystem.

The list of publications relating to optimal hydrographic surveys has a long history (e.g., Panteleev and Semenov, 1988; Beckers and Rixen, 2003). Here, we present a simple example of how the OSSE technique may help to optimize observations of passive tracers in the Chukchi Sea where intense and variable currents should be taken into account for the planning of surveys. The approach is based on the 4D-Var algorithm applied to an advection-diffusion differential equation, which describes the behavior of biological and hydrochemical content (such as small larvae, fish eggs, phosphates, and silicates) in a known velocity field. The approach was successfully used to reconstruct silicate, phosphate, and nitrate concentrations in the Bering Sea (Panteleev et al., 2013b).

To illustrate the approach, we utilize phosphate data sets collected in the southern Chukchi Sea during September 1990 (Fig. 3c) and realistic circulation reconstructed through the 4D-Var data assimilation approach (Panteleev et al., 2010). The phosphate observations were used to create initial conditions for the advective-diffusion equation, and then the temporal evolution of the phosphates in the Chukchi Sea was derived for a period of 7 days. Figure 3a and $3 \mathrm{~b}$ show phosphate and velocity fields at the beginning and at the end of the investigated period. Note that, under the intensive northward flow, the phosphates were advected almost $100 \mathrm{~km}$ northward.

The model solution of the realistic evolution of the phosphates in the Chukchi Sea was used for setting the observing system simulation experiments with the goal of understanding the effect of the regional circulation (advection) and the impact of the proper configuration of the survey on the accuracy of the final results that could be obtained from typical hydrophysical/ecosystem surveys. These issues are important because the hydrophysical and hydrochemical surveys are part of the AIERP plans in the Chukchi Sea (Fig. 4) and these OSSEs could be potentially useful for the optimization of incoming field experiments in the Chukchi Sea.

The mean "true" distribution of the passive tracer during 1-8 October 1990 is shown in Fig. 3c. A conventional passive tracer survey in the southern Chukchi Sea lasts approximately 7 days, during which hydrophysical and ecosystem (phosphate) tracer observations occur along the ship's path. There are multiple possible sample paths for the survey, a few of which are shown by black traces in Fig. 3d-f. Each path yields a different set of tracer observations since this passive tracer moves with the background velocity field. To analyze the efficiency of different surveys, we sample the "true" passive tracer along the proposed cruise tracks with a relative measurement error of $10 \%$.
Using the 4D-Var data assimilation algorithm applied to the advection-diffusion tracer model, the passive tracer field is reconstructed from observations taken along the two different survey paths. The root-mean-squared (RMS) difference between reconstructed and "true" distributions of the passive tracer is used as a metric to evaluate the efficiency of different surveys. Fig. 3e and f show that the ship's path (which define the survey observational operators) has a strong impact on the tracer field reconstruction, and an appropriate path may decrease the RMS by $50 \%$ and thereby reconstruct the tracer more accurately. Fig. 3d shows reconstructions obtained from the same ship paths shown in Fig. 3e using traditional optimal interpolation methods that do not account for the advection of passive tracers. This method is common in the analysis of hydrochemical and biological observations. Comparing Fig. 3d with Fig. 3e shows that use of the non-stationary 4D-Var data assimilation method allows for the reduction of the RMS by 50\%. Qualitatively, the results of the 4D-Var method (Fig. 3e, f) looks more realistic than the results of the optimal interpolation (Fig. 3d). The 4D-Var method allows for the reconstruction of the position and amplitude of the minimums and two maximums of the phosphate concentration in the location with coordinates $67^{\circ} \mathrm{N}$, $193^{\circ} \mathrm{E}, 67^{\circ} \mathrm{N}, 194^{\circ} \mathrm{E}$ and $67.9^{\circ} \mathrm{N}, 192^{\circ} \mathrm{E}$, while optimal interpolation had practically failed in the reconstruction of the maximums and significantly smoothed the observed minimum of the phosphates at $67^{\circ} \mathrm{N}, 193^{\circ} \mathrm{E}$.

The 4D-Var data assimilation approach allows for the reconstruction of the temporal evolution of phosphates (or other passive tracer) and, in the case of two sequential surveys, the 4D-Var data assimilation model can be modified and utilized for estimating the mortality coefficients of any passive tracer. A similar approach was utilized for the estimation of the mortality of fish eggs and small larvae during the field observation at the Nova Scotian shelf (Panteleev at al., 2004).

\section{EFFICIENT DRIFTER OBSERVATIONAL PROGRAM}

The examples presented above demonstrate that knowledge of the circulation is extremely important for the proper processing and analysis of the ecosystem observations and corresponding climate changes, especially in the regions with intensive currents. The velocity observations from moorings proved to be very useful for the reconstruction of the circulation in different regions. The reconstructed 1990-91 Chukchi Sea (CS) circulation (Fig. 3a, b; Panteleev et al., 2010) is a suitable example of an application of a 4D-Var algorithm, which includes in situ observations from moorings, CTD observations, and atmospheric forcing. Another example is the recent reconstruction of the circulation in the eastern Bering Sea using the 4D-Var nested data assimilation approach for 2007-10 (Panteleev et al., 2016). 

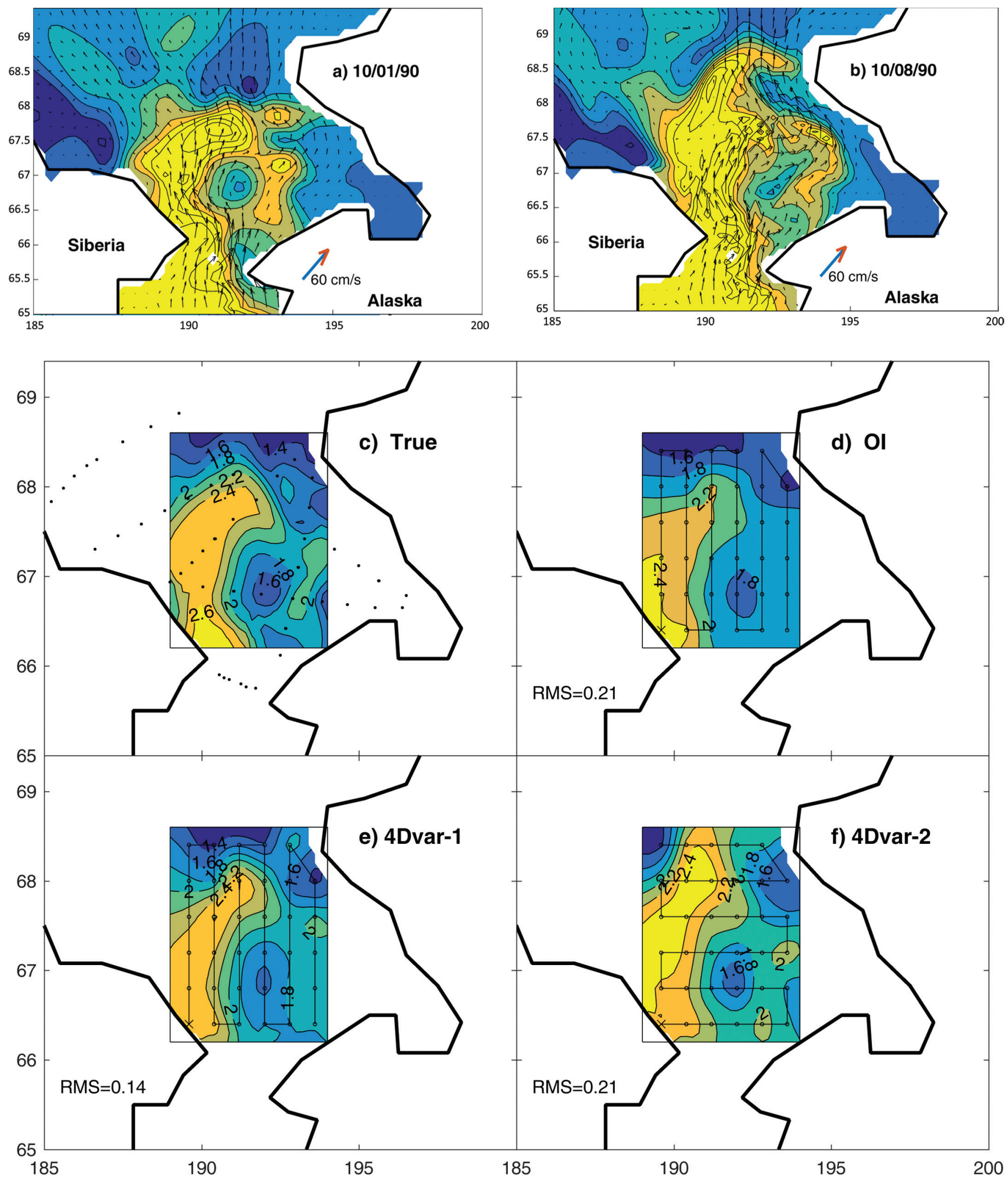

FIG. 3. a) Realistic circulation and b) phosphate distribution in the southern Chukchi Sea during 1-8 October 1990; c) temporally mean "true" phosphate averaged for the OSSE's region. Black dots designate the locations of the phosphate observations in September 1990 utilized for obtaining initial phosphate distribution (Fig. 3a); d) phosphate distributions derived from an idealized survey using a conventional optimal interpolation (OI); e) and f) temporally averaged phosphate distributions derived through $4 \mathrm{D}-\mathrm{Var}$ data assimilation of the observations derived from two possible surveys. Black $\times$ and dots designate the first station and direction of the surveys. The root-mean-squared (RMS) differences between the reconstructed and "true" phosphate distribution are shown. 


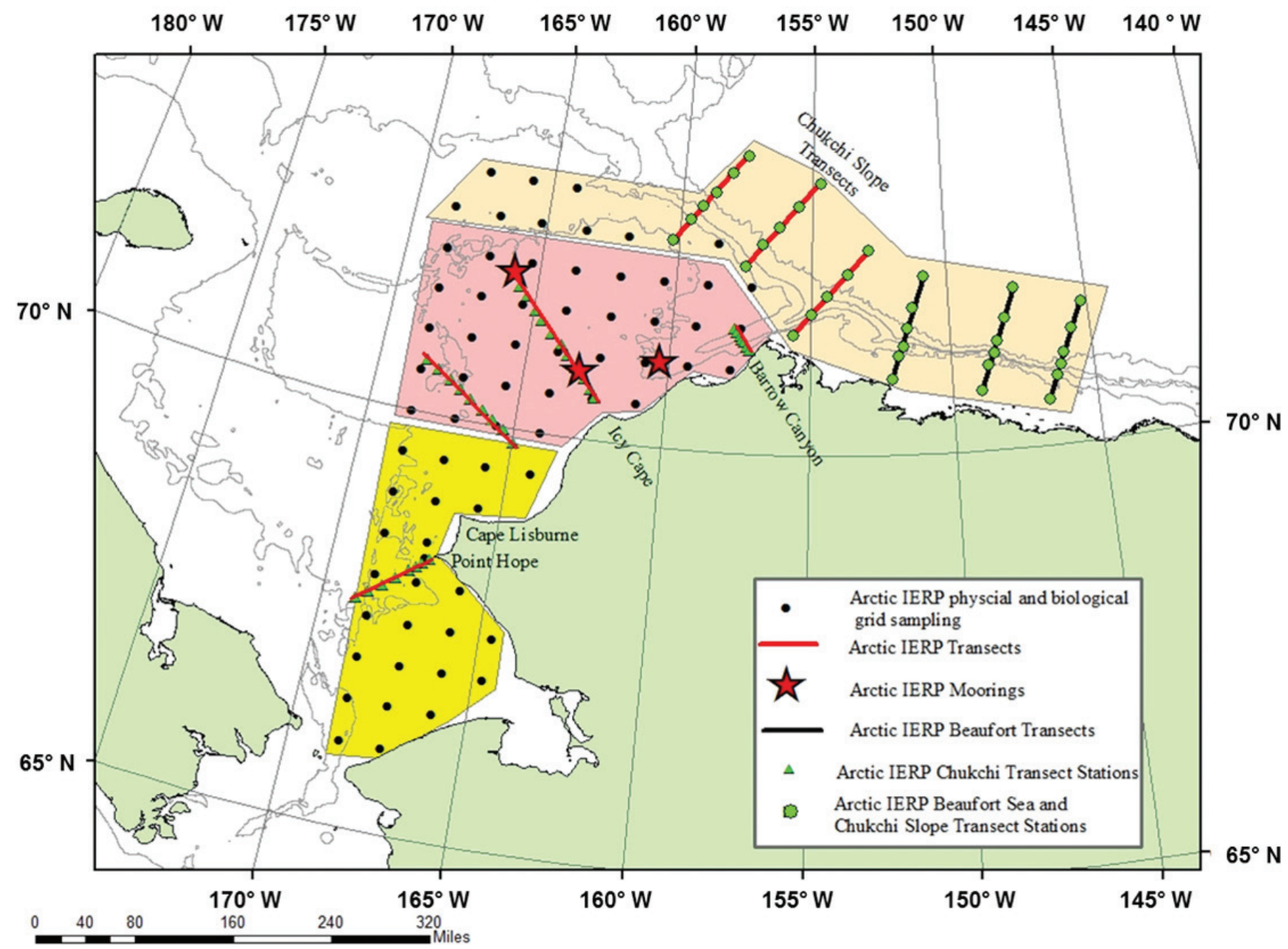

FIG. 4. Arctic Integrated Ecosystem Survey proposed by a team of NOAA researchers (North Pacific Research Board, Arctic Program http://www.nprb.org/ arctic-program/about-the-program/).

Presently, operational hindcast of the circulation is usually conducted through the assimilation of velocity observations from HFRs (Yu et al., 2012; Janeković et al., 2013). HFR observations in Alaska have been conducted since 2010 (Fang et al., 2017). However, Alaskan HFRs are usually located along the northern Alaskan coast (Wainwright, Barrow, Cape Simpson) and these HFRs do not describe the circulation in the central and southern part of the CS. Due to the remote location and severe winter conditions, HFRs along the Alaskan coast have to be taken down and redeployed every season, which costs approximately $\$ 150000$ for a pair of HFRs (Fang et al., 2017).

An alternative way to obtain operational velocity observations is through a distributed system of surface drifters. During the last decades, there were two intensive drifter observational programs in the Chukchi Sea. The first program included 39 surface drifters released in six clusters uniformly distributed along the Siberian coast in 1995. The analysis of these drifters shows that after 3-4 weeks, the drifters were uniformly spread in the East Siberian and Chukchi Seas, providing operational velocity and sea surface temperature data (Münchow et al., 1999).
Theoretically, this information could be used for the reconstruction of the circulation in the same way as the reconstruction and analysis of the Bering Sea circulation (Panteleev et al., 2011). It is important to note that an approximate drifter price is $\$ 2500-\$ 3000$ (e.g., MetOcean), so 39 drifters would cost about $\$ 100000-\$ 120000$. The additional cost of the ship time (RV Alpha Helix) needed to deliver the drifters to the East Siberian Sea had significantly increased the cost of the East Siberian Sea-Chukchi Sea drifter program in 1995.

In comparison with the drifter program in the East Siberian Sea, the drifter observations in the CS have several important advantages. First, the circulation in the CS has a persistent northward flow due to the difference in the sea surface height between the Arctic and Pacific Oceans (Coachman et al., 1975; Proshutinsky, 1986; Spaulding et al., 1987). Thus, drifters released in the southern part of the CS (e.g., in the Bering Strait) will gradually drift northward, providing velocity and temperature observations every 3-6 hours. In two months, some of the drifters will reach $72^{\circ} \mathrm{N}$ (Panteleev et al., 2010). Thus, if we gradually release drifters into the Bering Strait and (for example) near Point 


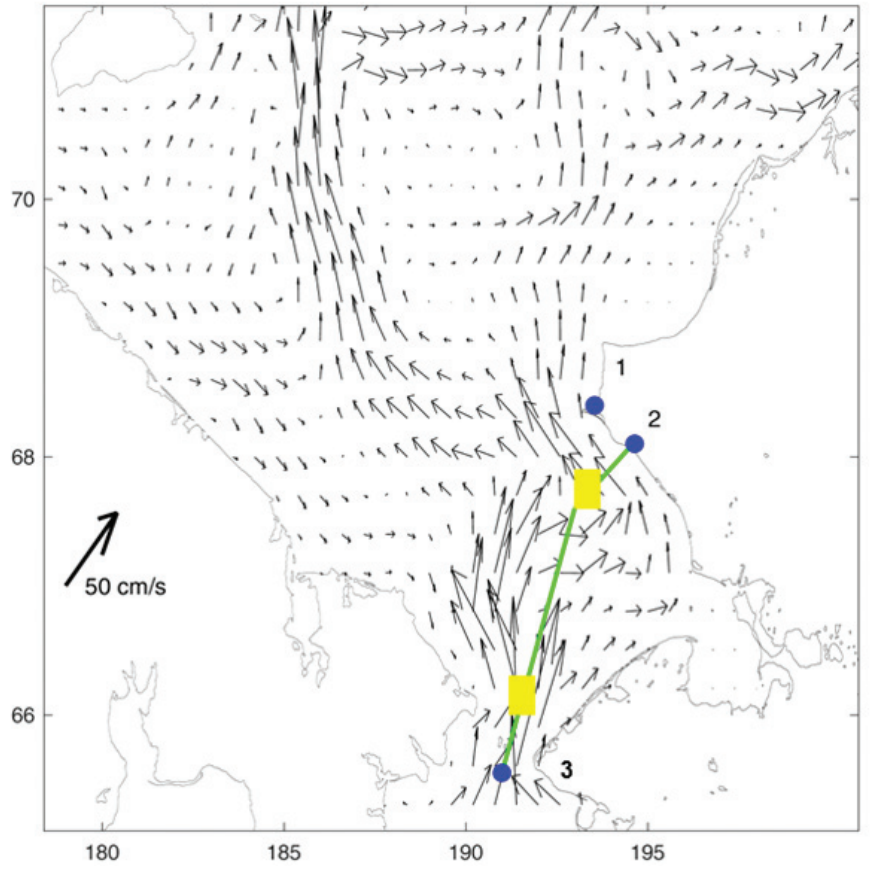

FIG. 5. Mean circulation in the Chukchi Sea during "warm" years (Luchin and Panteleev, 2014). Blue dots and numbers 1, 2, and 3 respectively designate Point Hope, Red Dog Port, and Diomede Island in the Chukchi Sea. The green line shows the path traveled by cargo ships from Red Dog Port to the Bering Strait. Yellow rectangles designate the locations of the surface drifter release discussed in "Efficient Drifter Observational Program."

Hope every 7-10 days, in $1-1.5$ months we may expect that our drifters will be more or less uniformly distributed along the two major pathways of the Pacific Water towards the Herald and Barrow Canyons (Fig. 5). Assimilation of the drifter velocity observations will allow for the reconstruction of the circulation of the entire CS.

Second, during the ice-free period, every 7-10 days a ship loaded by zinc ore leaves Red Dog Port headed towards the Bering Strait. These ships of opportunity allow for easy and free drifter deployment along the ship's routes; in particular, near the Bering Strait and Point Hope (Fig. 5).

Third, the Chukchi Sea is much deeper than the East Siberian Sea, which helps to avoid the grounding of drifters near the coast and the loss of drifter observations. Potentially, these advantages make the drifter observations very efficient and relatively inexpensive tools for the operational hindcast and forecast of the circulation in the CS during the ice-free period. Note that during the last decade, the ice-free period in the Chukchi Sea increased significantly, making drifter observations more attractive. To justify the potential attractiveness and efficiency of drifter observations in the Chukchi Sea, we conducted several OSSEs (discussed below).

As a model run mimicking a "true ocean" state, we utilized the realistic circulation from 15 July to 15 September 1991 derived through the assimilation of velocity, temperature, and salinity observations from 11 moorings (Panteleev et al., 2010). In the first OSSE, we mimicked drifter observations from 14 drifters gradually "released" into the water every nine days in the areas shown in Fig. 5 by yellow rectangles: one drifter in the Bering Strait and one near Red Dog Port. In the second and third OSSE, radial velocities from two HFRs deployed in Diomede-Wales (both looking northward) and Wales (looking northward)-Point Hope (looking southward) were assimilated. Climatological distribution of the temperature/ salinity with a zero-velocity field was used as a first guess.

The velocity map for the 51st day of the OSSEs and true solution, as well as relative errors of the reconstructions, are shown in Fig. 6. The most interesting result is that the "accumulated" drifter observations allow for a more accurate reconstruction of the circulation, with an error almost 1.5 times smaller than the reconstruction of the circulation with HFRs deployed in Diomede and Wales.

Note that four drifters drifted northwestward. We suggest that the effect of these four drifters resulted in a more realistic reconstruction of the circulation in the western Chukchi Sea, and especially in Long Strait and near the eastern flank of Wrangel Island. In particular, the small velocity of the drifter at $69^{\circ} \mathrm{N}, 186^{\circ} \mathrm{E}$ does not suggest intensive flow towards Long Strait. This information is missing in the HFR observations due to the limited $(200 \mathrm{~km})$ range. As a result, the model solution in the western part of the CS is not constrained by the HFR observations.

The assimilation of drifter observations outperforms the assimilation of the HFRs only after $\sim 1-1.5$ months, after first release of the two drifters in the Bering Strait and near Red Dog Port. During this period, 8-12 drifters became more or less uniformly distributed in the southern and central CS and the informational content of the drifter observations became more efficient than the observations from HFRs. In practice, this problem can be partly resolved by the additional deployment of drifters in the central part of the CS. OSSEs also show that after 2-3 weeks some of the drifters move to the northern CS, which significantly increases the quality of the reconstruction of the entire CS.

To analyze the possible impact of different HFR configurations and the additional HFR observations, we conducted three additional OSSEs: (1) two HFRs located in Wales (looking northward) and Point Hope (looking southward); (2) three HFRs in Wales, Point Hope, and Point Lay; and (3) four HFRs in Wales, Point Hope, Point Lay, and Wainwright. The areas covered by utilized HFRs, the reconstructed circulation on the 51st day of each OSSE, and corresponding errors of the reconstruction are shown in Fig. $6 \mathrm{~b}-\mathrm{f}$.

The result of these OSSEs is rather interesting. According to Figure 6a and 6b, the HFR configuration of Wales (looking northward)-Point Hope (looking southward) allows for a more accurate reconstruction of the circulation than the observations from Diomede-Wales (both looking northward) HFRs. This result is similar to that of the OSSE with two HFRs installed on Diomede Island. Thus, the configuration of the HFRs without the intersection of the coverage areas could be, in some regions, rather efficient for the accurate reconstruction of the circulation. 

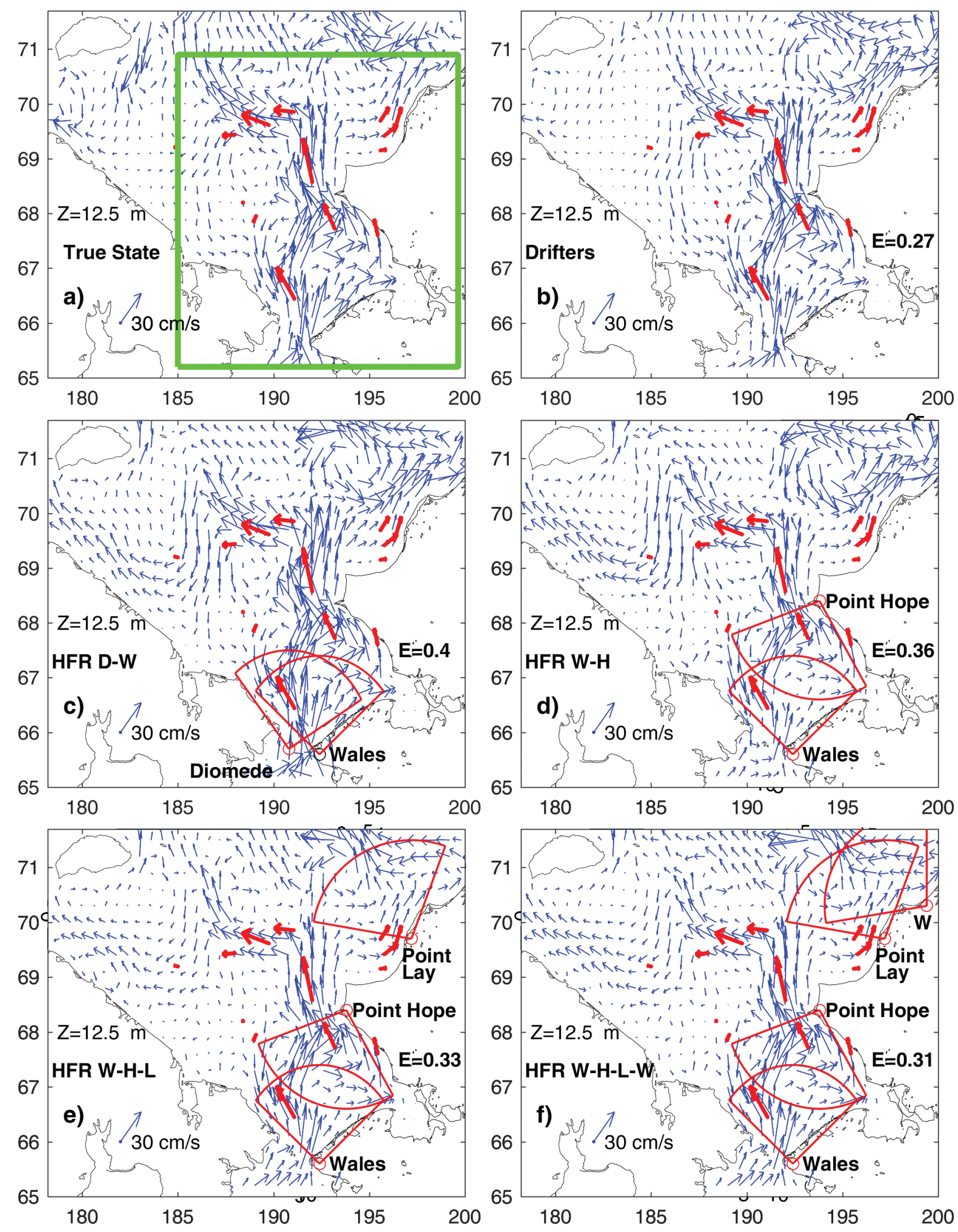

FIG. 6. Results of the OSSEs: a) "True" velocity state at $12 \mathrm{~m}$ after 51 days; b) circulation reconstructed through the assimilation of velocities from 14 drifters released near Red Dog Port and in the Bering Strait; c) to f) circulations reconstructed through the assimilation of HFR radial velocities installed in Diomede and Wales; in Wales and Point Hope; in Wales, Point Hope and Point Lay; and in Wales, Point Hope, Point Lay, and Wainwright. The regions covered by HFRs are marked by black dots. Relative errors of the reconstruction estimated for the square domain is shown in a), and the drifter velocities (thick red arrows) are shown at each subplot. 


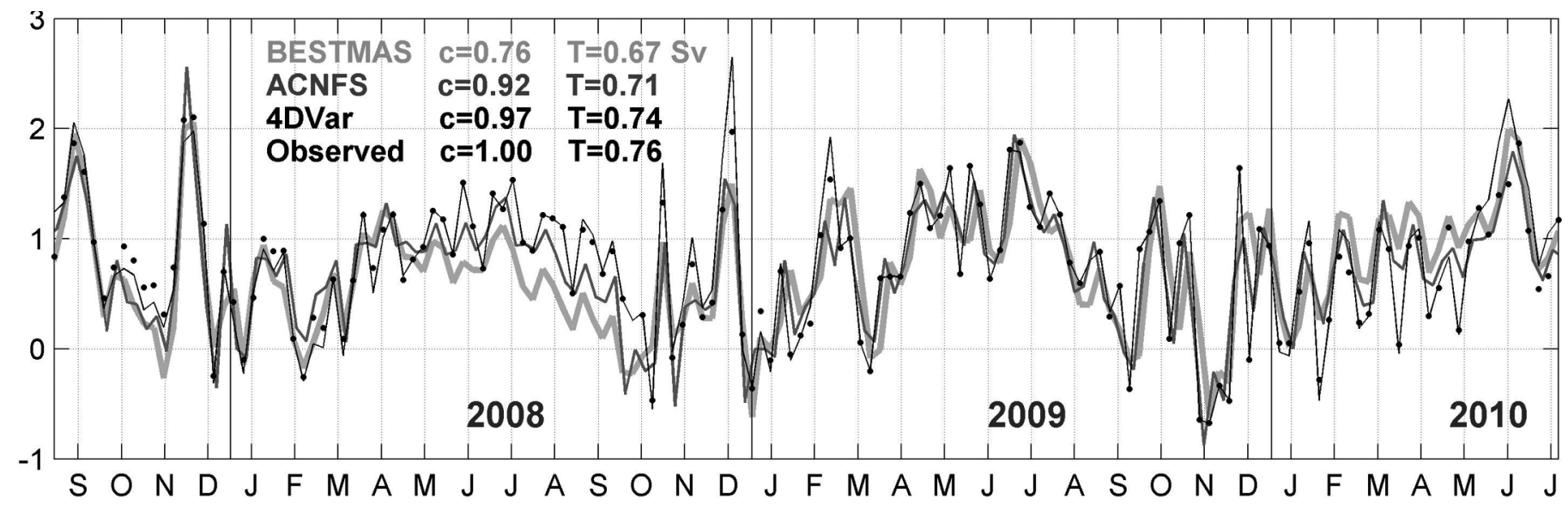

FIG. 7. Weekly averaged Bering Strait transports (Sv) in the optimized solution (solid black line), and from the ACNFS (gray) and Bering Ecosystem Study iceocean Modeling and Assimilation System (BESTMAS) (light gray) output. Observed values are shown by solid dots. The time-averaged values of the transport $\mathrm{T}$ and correlation coefficients $\mathrm{c}$ with observations are given.

The observations from additional HFRs installed in Point Lay and Wainwright only slightly improve the errors of the reconstruction. This finding is probably due to the persistent northward flow along the Alaskan coast and the correlation of the velocities in the southern and northern parts of the Alaskan Coastal current. Thus, additional observations from the HFRs in Point Lay and Wainwright correlate with observations in the southern part of the CS from HFRs in Wales and Point Hope. Because of this correlation, additional HFR observations do not significantly impact the accuracy of the reconstructed circulation.

Remarkably, the assimilation of the observations from three and four HFRs also does not allow for the accurate reconstruction of the circulation in the western part of the CS. All reconstructed HFR circulations (Fig. 6c and d) clearly indicate a strong northwestward current, which does not exist in the "true" circulation (Fig. 6a). This difference is due to the limited range of the HFR, which provides velocity observations only up to $200 \mathrm{~km}$ from the Alaskan coast.

The demonstrated OSSEs show that the preliminary analysis of the planned observational system may significantly improve the efficiency of the collected observations. The result of the OSSEs significantly depends on the regional circulation pattern and, in any particular case, should be validated through the OSSE or ASA approaches. Note also that in the OSSEs discussed above, we neglected the drifter temperature observations. The additional temperature/salinity information from the drifters, shipborne CTDs, and radial velocities from HFRs along the northern Alaskan coast will increase the accuracy of the reconstructed circulation.

The OSSEs shown in Fig. 6 were conducted for a period of two months. The drifter observational program for an entire ice-free period ( $4-5$ months) will need approximately 30 drifters. The annual drifter program of 30 drifters costs only $\$ 70000$, which is a much smaller amount than the $\$ 150000$ required for supporting a pair of HFRs during the summer season in Alaska (Fang et al., 2017). Thus, the conducted OSSEs clearly show the feasibility and efficiency of the regional Chukchi Sea observational system based on drifters. It is important, however, that the process of drifter release should be operationally controlled by OSSEs based on a regional data assimilation system. The "uncontrollable" release of drifters during one expedition, which is actually a typical practice, will not allow for an accurate reconstruction of the circulation during a relatively long period of time (1.5-4 months) since the drifters will gradually move northward and the collected information will be insufficient to monitor the circulation in the southern part of the Chukchi Sea.

\section{CONCLUSIONS}

The ASA and OSSE algorithms have been successfully used by agencies such as the National Aeronautics and Space Administration, the National Oceanic and Atmospheric Administration, Meteo France, and the Met Office in the United Kingdom for the planning and testing of new observational systems in atmospheric science. Recently, the OSSEs were also applied for estimating errors of the observing network in the northwestern Mediterranean Sea (Waldman et al., 2016).

Obviously, both of these approaches have a strong potential for optimizing the existing and incoming observational programs in the Arctic Ocean and should be adopted for the planning and post-processing of the collected observations. Application of these approaches will allow significant savings of limited financial resources and ship time and will maximize the informational content of collected in situ observations.

Currently, these approaches can be easily applied for such planning using the existing (previously reconstructed climatological or seasonal) circulations. Both algorithms can be also routinely incorporated into a web server and become available for practically any qualified user. There 
is also a straightforward opportunity to develop a similar web server for optimizing passive tracer surveys. However, these optimization systems and web servers will be designed for optimization with respect to previously known (e.g., climatological) regional circulations. It is reasonable to use climate circulation for the planning of long-term observation programs (such as mooring deployment and HFR installation sites), but a practical survey optimization system would require an operational circulation model.

Our analysis of the circulation from the Arctic Cap Nowcast/Forecast System developed in the Naval Research Laboratory (Posey et al., 2010) shows that the system provides accurate estimates of the circulation in the southern Chukchi Sea. In particular, the Bering Strait transport from ACNFS has a 0.92 correlation with observed volume transport (Fig. 7). The Bering Strait throughflow is the dominant forcing control of the southern Chukchi Sea, and therefore the ACNFS velocity field can be recommended as a first-guess state for various data assimilation algorithms, including the ones described above. Thus, access to the operational output from the ACNFS would facilitate the development of online tools for operational survey optimization in the Chukchi Sea via OSSE and for post-processing of these observations using the advection-diffusion approach.

\section{ACKNOWLEDGEMENTS}

This study was supported by the International Arctic Research Center, NSF grants 1107925, 1203740, and ONR grant "Arctic ice data assimilation." We also thank the Russian government (grant no. 14, Z50.31.0012/03.19.2014) and (p220/mega-grant 2013-22004-157) and the University of Hawai'i at Manoa for support. We would also like to thank two reviewers who donated their time and reviewed our manuscript for Arctic.

\section{REFERENCES}

Baker, N.L., and Daley, R. 2000. Observation and background adjoint sensitivity in the adaptive observation-targeting problem. Quarterly Journal of the Royal Meteorological Society 126(565):1431-1454.

https://doi.org/10.1002/qj.49712656511

Barth, N.H. 1992. Oceanographic experiment design II: Genetic algorithms. Journal of Atmospheric and Oceanic Technology 9:434-443.

https://doi.org/10.1175/1520-0426(1992)009<0434:OEDIGA >2 $0 . \mathrm{CO} ; 2$

Barth, N.H., and Wunsch, C. 1990. Oceanographic experiment design by simulated annealing. Journal of Physical Oceanography 20:1249-1263.

https://doi.org/10.1175/1520-0485(1990)020<1249:OEDBSA $>2$ .0.CO;2
Beckers, J.M., and Rixen, M. 2003. EOF calculations and data filling from incomplete oceanographic datasets. Journal of Atmospheric and Oceanic Technology 20:1839-1856.

https://doi.org/10.1175/1520-0426(2003)020<1839:ECADFF $>2$ .0.CO;2

Bennett, A.F. 1985. Array design by inverse methods. Progress in Oceanography 15(2):129-156.

https://doi.org/10.1016/0079-6611(85)90033-3

BGEP (Beaufort Gyre Exploration Project). 2016. Background. http://www.whoi.edu/website/beaufortgyre/home

Bishop, C.H., Etherton, B.J., and Majumdar, S.J. 2001. Adaptive sampling with the ensemble transform Kalman filter. Part I: Theoretical aspects. Monthly Weather Review 129:420-436. https://doi.org/10.1175/1520-0493(2001)129<0420:ASWTET> 2.0.CO;2

Cacuci, D.G. 2003. Sensitivity and uncertainty analysis, Vol. 1: Theory. a primer. Boca Raton, Florida: CRC Press. 304 p.

Coachman, L.K., Aagaard, K., and Tripp, R.B. 1975. Bering Strait: The regional physical oceanography. Seattle: University of Washington Press. 172 p.

Daescu, D.N., and Navon, I.M. 2004. Adaptive observations in the context of 4D-Var data assimilation. Meteorology and Atmospheric Physics 85(4):205-226. https://doi.org/10.1007/s00703-003-0011-5

Errico, R.M., Yang, R., Privé, N.C., Tai, K.-S., Todling, R., Sienkiewicz, M.E., and Guo, J. 2013. Development and validation of observing-system simulation experiments at NASA's Global Modeling and Assimilation Office. Quarterly Journal of the Royal Meteorological Society 139(674):1162-1178. https://doi.org/10.1002/qj.2027

Fang, Y.-C., Potter, R.A., Statscewich, H., Weingartner, T.J., Winsor, P., and Irving, B.K. 2017. Surface current patterns in the northeastern Chukchi Sea and their response to wind forcing. Journal of Geophysical Research: Oceans 122(12):9530-9547. https://oi.org/10.1002/2017JC013121

Francis, O.P., Panteleev, G.G., and Atkinson, D.E. 2011. Ocean wave conditions in the Chukchi Sea from satellite and in situ observations. Geophysical Research Letters 38, L24610. https://doi.org/10.1029/2011GL049839

JAMSTEC (Japan Agency for Marine-Earth Science and Technology). 2017. JAMSTEC Compact Arctic Driver (J-CAD).

http://www.jamstec.go.jp/e/database/

Janeković, I., Powell, B.S., Matthews, D., McManus, M.A., and Sevadijan, J. 2013. 4D-Var data assimilation in a nested, coastal ocean model: A Hawaiian case study. Journal of Geophysical Research Oceans 118(10):5022-5035. https://doi.org/10.1002/jgrc.20389

Köhl, A., and Stammer, D. 2004. Optimal observations for variational data assimilation. Journal of Physical Oceanography 34:529-542.

https://doi.org/10.1175/2513.1 
Lahoz, W.A., Brugge, R., Jackson, D.R., Migliorini, S., Swinbank, R., Lary, D., and Lee, A. 2005. An observing system simulation experiment to evaluate the scientific merit of wind and ozone measurements from the future SWIFT instrument. Quarterly Journal of the Royal Meteorological Society 131(606):503 - 523. https://doi.org/10.1256/qj.03.109

Luchin, V., and Panteleev, G. 2014. Thermal regimes in the Chukchi Sea from 1941 to 2008. Deep Sea Research Part II: Topical Studies in Oceanography 109:14-26. https://doi.org/10.1016/j.dsr2.2014.05.007

Marchuk, G.I. 1995. Adjoint equations and analysis of complex systems. Mathematics and Its Applications Series, Vol. 295. Dordrecht, The Netherlands: Kluwer Academic Publishers. $463 \mathrm{p}$. https://doi.org/10.1007/978-94-017-0621-6

Morison, J., Kwok, R., Peralta-Ferriz, C., Alkire, M., Rigor, I., Andersen, R., and Steele, M. 2012. Changing Arctic Ocean freshwater pathways. Nature 481:66-70.

https://doi.org/10.1038/nature10705

Münchow, A., Weingartner, T.J., and Cooper L.W. 1999. The summer hydrography and surface circulation of the East Siberian Shelf Sea. Journal of Physical Oceanography 29:2167-2182.

https://doi.org/10.1175/1520-0485(1999)029<2167:TSHASC $>2$. $0 . \mathrm{CO} ; 2$

NABOS (Nansen and Amundsen Basins Operational System). 2016. NABOS and CABOS (Canadian Basin Observational System): Proposed monitoring system of the Arctic Ocean. http://nabos.iarc.uaf.edu/

Panteleev, G.G., and Semenov, E.V. 1988. On the strategy of hydrological array measurements. Oceanologia 28(6):1032-1034.

Panteleev, G.G., deYoung, B., Reiss, C., and Taggart, C. 2004. Passive tracer reconstruction as a least squares problem with a semi-Lagrangian constraint: An application to fish eggs and larvae. Journal of Marine Research 62(6):787-814. https://doi.org/10.1357/0022240042880846

Panteleev, G., Yaremchuk, M., and Nechaev, D. 2009. Optimization of mooring observations in northern Bering Sea. Dynamics of Atmospheres and Oceans 48(1-3):143-154. https://doi.org/10.1016/j.dynatmoce.2008.11.004

Panteleev, G., Nechaev, D.A., Proshutinsky, A., Woodgate, R., and Zhang, J. 2010. Reconstruction and analysis of the Chukchi Sea circulation in 1990-1991. Journal of Geophysical Research Oceans 115, C08023. https://doi.org/10.1029/2009JC005453

Panteleev, G., Yaremchuk, M., Stabeno, P.J., Luchin, V., Nechaev, D.A., and Kikuchi, T. 2011. Dynamic topography of the Bering Sea. Journal of Geophysical Research Oceans 116, C05017. https://doi.org/10.1029/2010JC006354

Panteleev, G., Yaremchuk, M., Francis, O., and Kikuchi, T. 2013a. Configuring high frequency radar observations in the southern Chukchi Sea. Polar Science 7(2):72-81. https://doi.org/10.1016/j.polar.2013.01.001
Panteleev, G., Luchin, V., Nezlin, N.P., and Kikuchi, T. 2013 b. Seasonal climatologies of oxygen and phosphates in the Bering Sea reconstructed by variational data assimilation approach. Polar Science 7(3-4):214-232. https://doi.org/10.1016/j.polar.2013.10.001

Panteleev, G., Yaremchuk, M., Stroh, J., Posey, P., Hebert, D., and Nechaev, D.A. 2015. Optimization of the high-frequency radar sites in the Bering Strait region. Journal of Atmospheric and Oceanic Technology 32:297-309. https://doi.org/10.1175/JTECH-D-14-00071.1

Panteleev, G., Yaremchuk, M., Francis, O., Stabeno, P.J., Weingartner, T., and Zhang, J. 2016. Inverse modeling of the circulation in the eastern Bering Sea during 2007-2010. Journal of Geophysical Research Oceans 121(6):3970-3989. https://doi.org/10.1002/2015JC011287

Posey, P.G., Metzger, E.J., Wallcraft, A.J., Preller, R.H., Smedstad, O.M., and Phelps, M.W. 2010. Validation of the 1/12 degrees Arctic Cap Nowcast/Forecast System (ACNFS). Naval Research Lab Report. Fort Belvoir, Virginia: Defense Technical Information Center. https://doi.org/10.21236/ada533597

Proshutinsky, A. 1986. Calculation surge fluctuations in the level and circulation of water of the Chukchi Sea. Meterologiya $i$ Gidrologiya 1:54-61.

Qiao, F., Yuan, Y., Yang, Y., Zheng, Q., Xia, C., and Ma, J. 2004. Wave-induced mixing in the upper ocean: Distribution and application to a global ocean circulation model. Geophysical Research Letters 31, L11303. https://doi.org/10.1029/2004GL019824

Simmonds, I., and Rudeva, I. 2012. The great Arctic cyclone of August 2012. Geophysical Research Letters 39, L23709. https://doi.org/10.1029/2012gl054259

Spaulding, M., Isaji, T., Mendelsohn, D., and Turner, A.C. 1987. Numerical simulation of wind-driven flow through the Bering Strait. Journal of Physical Oceanography 17:1799-1816. https://doi.org/10.1175/1520-0485(1987)017<1799:NSOWDF >2 .0.CO;2

Timmermans, R.M.A., Lahoz, W.A., Attié, J.-L., Peuch, V.-H., Curier, R.L., Edwards, D.P., Eskes, H.J., and Builtjes, P.J.H. 2015. Observing system simulation experiments for air quality. Atmospheric Environment 115:199-213.

https://doi.org/10.1016/j.atmosenv.2015.05.032

Waldman, R., Somot, S., Herrmann, M., Testor, P., Estournel, C., Sevault, F., Prieur, L., et al. 2016. Estimating dense water volume and its evolution for the year 2012-2013 in the northwestern Mediterranean Sea: An observing system simulation experiment approach. Journal of Geophysical Research Oceans 121(9):6696-6716. https://doi.org/10.1002/2016JC011694

WHOI (Woods Hole Oceanographic Institute). 2007. Ice-tethered profiler: An autonomous instrument for sustained observation of the Arctic Ocean. http://www.whoi.edu/page.do?pid=20756 
Woodgate, R.A., Weingartner, T.J., and Lindsay, R. 2012. Observed increases in Bering Strait oceanic fluxes from the Pacific to the Arctic from 2001 to 2011 and their impacts on the Arctic Ocean water column. Geophysical Research Letters 39, L24603.

https://doi.org/10.1029/2012GL054092

Wunsch, C. 1996. The ocean circulation inverse problem. Cambridge: Cambridge University Press.

https://doi.org/10.1017/CBO9780511629570

\section{APPENDIX 1}

Let $\boldsymbol{y}_{\mathrm{o}}$ provide a minimum to the quadratic cost function $J$, and $\delta \boldsymbol{y}$ be small deviations from $\boldsymbol{y}_{0}$. Then a variation $\delta J$ of $J$ from its value at the minimum is

$$
\delta J=1 / 2 \delta \boldsymbol{y}^{\mathrm{T}} \mathbf{B}^{-1} \delta \boldsymbol{y}=1 / 2 \delta \boldsymbol{c}^{\mathrm{T}} \mathbf{M}^{\mathrm{T}} \mathbf{B}^{-1} \mathbf{M} \delta \boldsymbol{c}
$$

where $\mathbf{B}^{-1}$ is a non-negative definite matrix, interpreted as the inverse error covariance matrix in the space of model trajectories. Assume that $n$ additional observations $\boldsymbol{d}$ of the state vector $\boldsymbol{y}$ are made such that $\boldsymbol{d}=\mathbf{L}_{1} \boldsymbol{y}+\boldsymbol{e}$, where $\boldsymbol{e}$ is the observational noise with (diagonal) covariance $\mathbf{R}$, and $\mathbf{L}_{1}$ is the linear operator mapping the state to observations. Given these new data, the variation of the cost function (A1) should be augmented with the additional term

$$
\delta J \Rightarrow \delta J+1 / 2\left(\mathbf{L}_{1} \delta \boldsymbol{y}+\delta \boldsymbol{d}\right)^{\mathrm{T}} \mathbf{R}^{-1}\left(\mathbf{L}_{1} \delta \boldsymbol{y}+\delta \boldsymbol{d}\right)
$$

where $\delta \boldsymbol{d}=\mathbf{L}_{1} \boldsymbol{y}_{\mathrm{o}}-\boldsymbol{d}$ and $\delta \boldsymbol{y}$ is the perturbation of the optimal state caused by the cost function update. It follows from (A1) - (A2) that the updated error covariance is $\mathbf{B}_{\mathrm{d}}=$ $\left(\mathbf{B}^{-1}+\mathbf{L}_{1}{ }^{\mathbf{T}} \mathbf{R}^{-1} \mathbf{L}_{1}\right)^{-1}$. Using the Woodbury identity, it can be rewritten in the form

$$
\mathbf{B}_{\mathrm{d}}=\mathbf{B}-\mathbf{B L}^{\mathrm{T}} \mathbf{W}_{\mathrm{B}}{ }^{-1} \mathbf{L} \mathbf{B}
$$

where $\mathbf{R}_{\mathrm{B}}=\mathbf{R}+\mathbf{L}_{1} \mathbf{B L}_{1}{ }^{\mathbf{T}}$. Since both terms on the righthand side of (A3) are nonnegative definite, adding new observations always reduces the overall error variance described by the trace of $\mathbf{B}_{\mathrm{d}}$.

In oceanographic practice, observational arrays are often specifically designed for monitoring physically important (target) quantities $q$, such as mass, heat or freshwater transports through certain sections. Assuming that $q$ is linearly related to the ocean state $y$, via the relationship $q=\mathbf{L}_{2} \boldsymbol{y}$ we can deduce that with additional observations described by the operator $\mathbf{L}_{1}$ the total error variance of the target quantity $\mathbf{B}^{q}=\mathbf{L}_{2} \mathbf{B} \mathbf{L}_{2}{ }^{\mathrm{T}}$ is reduced by

$$
\begin{gathered}
\operatorname{Tr} \delta \mathbf{B}^{q}=\operatorname{Tr}\left[\mathbf{B}^{q}-\mathbf{B}^{q} d\right] \\
=\operatorname{Tr}\left[\mathbf{L}_{2} \mathbf{B} \mathbf{L}_{1}{ }^{\mathbf{T}} \mathbf{R}_{\mathrm{B}}{ }^{-1} \mathbf{L}_{1} \mathbf{B} \mathbf{L}_{2}{ }^{\mathbf{T}}\right]=\operatorname{Tr}\left[\mathbf{S}^{\mathbf{T}} \mathbf{S}\right],
\end{gathered}
$$

Yu, P., Kurapov, A.L., Egbert, G.D., Allen, J.S., and Kosro, P.M. 2012. Variational assimilation of HF radar surface currents in a coastal ocean model off Oregon. Ocean Modelling 49-50:86- 104.

https://doi.org/10.1016/j.ocemod.2012.03.001

where

$$
\mathbf{S}=\mathbf{R}_{\mathrm{B}}{ }^{-1 / 2} \mathbf{L}_{1} \mathbf{B} \mathbf{L}_{2}{ }^{\mathbf{T}}
$$

is the sensitivity matrix of $q=\mathbf{L}_{2} \boldsymbol{y}$ with respect to observations described by $\mathbf{L}_{1}$ (e.g., Kohl and Stammer, 2004). Equation (A5) is similar to the expression for the "observation sensitivity" $\mathbf{S}_{\mathrm{o}}$ formulated in (Baker and Daley, 2000) in terms of the Kalman gain matrix $\mathbf{K}=$ $\mathbf{B} \mathbf{L}_{1}{ }^{\mathrm{T}} \mathbf{R}_{\mathrm{B}}{ }^{-1}$ as $\mathbf{S}_{\mathrm{o}}=\left(\mathbf{L}_{2} \mathbf{K}\right)^{\mathrm{T}}$.

When both the new data and the target quantity are scalars, $\mathbf{L}_{1,2}$ are the row vectors, and sensitivity matrix $\mathbf{S}$ is a scalar depending on the prior covariance $\operatorname{cov}\left(q_{1}, q_{2}\right)$ $=\mathbf{L}_{1} \mathbf{B L}_{2}{ }^{\mathbf{T}}$. Nevertheless, even in this simple case, the computation of the sensitivity is computationally demanding, mostly because of the huge size of $\mathbf{B}$. Furthermore, computing the action of $\mathbf{B}$ on a column vector $\mathbf{L}_{2}{ }^{\mathbf{T}}$ in (A5) is not straightforward because the cost function (A1) is formulated in terms of the sparse rank-deficient matrix $\mathbf{B}^{-1}$. This action may be calculated by inverting $\mathbf{B}^{-1}$ in the subspace spanned by the variations of the control variables used in the optimization process. Using $\mathbf{H}_{c}^{-1}$ to denote this inverse, the sensitivity matrix takes the form

$$
\mathbf{S}=\mathbf{R}^{-1 / 2} \mathbf{L}_{1} \mathbf{M} \mathbf{H}_{c}^{-1} \mathbf{M}^{\mathrm{T}} \mathbf{L}_{2}{ }^{\mathbf{T}}
$$

The reduced-space Hessian inverse $\mathbf{H}_{c}^{-1}$ has a significantly smaller dimension than $\mathbf{B}$ and was approximated by the low-rank error covariance matrix retrieved from the data assimilative run of the ACNFS. The matrix $\mathbf{M}$ is implicitly given by the OGCM code, linearized in the vicinity of the optimal model trajectory $\boldsymbol{y}_{0}$, while the code for computing the action of $\mathbf{M}^{\mathbf{T}}$ on a state vector is available in the form of the adjoint model. In obtaining the results discussed in "Optimal Positioning of HFR," we found that observation errors $\mathbf{R}$ of surface velocities $(5-8 \mathrm{~cm} / \mathrm{s})$ by HFRs were significantly larger than the respective diagonal elements of $\mathbf{L}_{1} \mathbf{B} \mathbf{L}_{1}{ }^{\mathrm{T}}$ and neglected them in computing the respective sensitivities by setting $\mathbf{R}_{\mathrm{B}}=\mathbf{R}$. (cf. eqns. A5 and A6). 